\title{
Action Plan and Status of Resolutions for LWRS Steering Committee Recommendations Dated August 13, 2009
}

August 2009

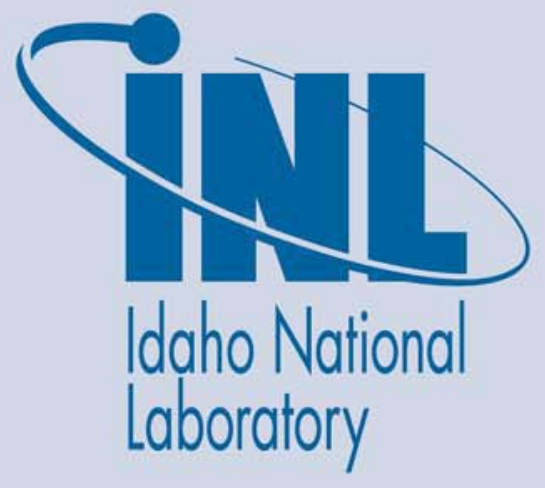

The INL is a U.S. Department of Energy National Laboratory operated by Battelle Energy Alliance 
INL/EXT-09-17515

\title{
Action Plan and Status of Resolutions for LWRS Steering Committee Recommendations Dated August 13, 2009
}

August 2009

\author{
Idaho National Laboratory \\ Idaho Falls, Idaho 83415
}

http://www.inl.gov

Prepared for the

U.S. Department of Energy

Office of Nuclear Energy

Under DOE Idaho Operations Office

Contract DE-AC07-05ID14517 
INL/EXT-09-17515

\section{Action Plan and Status of Resolutions for LWRS Steering Committee Recommendations Dated August 13, 2009}


INL/EXT-09-17515

Revision 0

This is a living document for planning and status of the Steering Committee's Light Water Reactor Sustainability (LWRS) recommendations, which were provided by their report, dated August 13, 2009.

The report presented here is a subset of the LWRS Program Plan, which represents the complete research and development (R\&D) plan for the LWRS Program; it has been reissued in December 2009 (Revision 2).

As the recommendations are resolved, this plan will be updated to reflect current status in future revisions of the Program Plan. 
INL/EXT-09-17515

Revision 0

Recommendation 1: III-A. The LWRS management team should seek a clearer understanding of the intent of senior DOE management regarding how "science-based" is to be interpreted and articulate its approach to implementing this interpretation.

Page: 18

Specific Related Steering Committee Observations and Page:

Resolution: Agree with recommendation.

The definition of "science-based" approach will be explored with guidance from DOE NE-1. The TIO will work through the DOE LWRS Program managers to get a clear definition of "science-based" approach before the next Steering Committee meeting in June 2010. 
INL/EXT-09-17515

Revision 0

Recommendation 2: III-B. Rationale for the LWRS Program as a national priority - The importance of maintaining operation of the existing LWR fleet has been recognized by governing and scientific bodies as a national priority as evidenced by the extracted segments of their documentation displayed earlier. Hence the Office of NE and the LWRS Program need to take effective action to brand the LWRS Program as a national priority.

\section{Page: 18}

\section{Specific Related Steering Committee Observations and Page:}

-----Based on potential LWR operational R\&D needs, it is not unreasonable to estimate that $\$ 100 \mathrm{M} / \mathrm{yr}$ total would be required over 20 years. Assuming a funding share arrangement of $45 / 45 / 10 \%$ for DOE/industry/NRC respectively, that yields a $\$ 900 \mathrm{M}$ phase a) Program for DOE, or a factor of about 5 times greater than the existing Program cost estimate (\$200M).-----Page 8.

Resolution: Agree with recommendation.

- $\quad$ Recently, the LWRS TIO participated in a DOE laboratories-led roadmap exercise for DOE-NE, identifying necessary and appropriate nuclear energy R\&D. The importance of the LWRS Program as a national need has been recognized by the roadmap. The roadmap identified Five Imperatives for DOE NE to focus on. Imperative 1 of that roadmap is to "extend life, improve performance, and maintain safety of the current fleet." The report stated, "The DOE RD\&D role will appropriately focus on aging phenomena and issues that require long-term research and are generic to reactor type. Some cost-shared DOE demonstration activities may be conducted when appropriate."

- $\quad$ Planning and actions have been initiated to establish the basis and effectively communicate the reasons and importance for a national priority of LWRS Program and substance of the program. The aims and size of the program are contained in a 5-year program plan, which will be released by December 31, 2009.

- A draft 10-year program plan will be released before the next Steering Committee meeting.

- $\quad$ DOE will develop an MOU with EPRI to address the cost share program. The MOU will be issued before the next Steering Committee meeting in June 2010.

- A Stakeholder Engagement Plan is being developed by TIO and will cover interactions and communications with the industry (e.g., utilities, vendors, EPRI, and NEI), regulators, universities and international bodies. It will be issued in June 2010 following completion of the DOE and EPRI MOU and will lead to publication and communication plans with technical and nontechnical stakeholders. 
INL/EXT-09-17515

Revision 0

Recommendation 3: III-C. The LWRS Program plan should cite Recommendation 2-7 of the NAS study whenever this study is referred to.

\section{Page: 18}

\section{Specific Related Steering Committee Observations and Page:}

Recommendation 2-7 of the NAS study is copied in the following:

"DOE should evaluate the need for a reinvigorated R\&D program to improve the performance of existing nuclear plants in a DOE-industry cost-shared effort separate from NP 2010. The estimated benefits to society should substantially exceed the government investment. In the event of funding constraints, NP 2010 funding for new plant deployment should have priority over this R\&D for LWRs."

Resolution: Agree with recommendation and have implemented it. 
INL/EXT-09-17515

Revision 0

Recommendation 4: IV-A. The Committee recommends that the exclusive scope of this Program should be achieving the safe and economical long term operation of the existing fleet of US light water reactors.

Page: 20

Specific Related Steering Committee Observations and Page:

Resolution: Agree with recommendation. The focus and justification for the program will be long-term operation of the current fleet. However, there should be spinoffs important to future plants. 
INL/EXT-09-17515

Revision 0

Recommendation 5: IV-B. The Committee recommends that TIO should consider adding an additional Pathway on activities of relevance to environmental impacts on long term operation. Additionally the TIO should monitor the development of a separate program on R\&D for enhancement of the security of the operating fleet. Monitoring only is recommended because of the specific nature of the secure means by which such research should be conducted and the results controlled.

Page: 21

\section{Specific Related Steering Committee Observations and Page:}

Resolution: Agree with adding an additional pathway on activities of relevance to environmental impacts on long-term operation.

- $\quad$ An additional pathway, Efficiency and Economics Improvement (will later be named Environmental Reliability and Economics Improvement), has been added. The initial thrust is the cooling water usage issues and technology to reduce environmental impact on power uprates and long-term operation.

- $\quad$ Currently, there is no plan to address the enhancement of the security of the operating fleet. 
INL/EXT-09-17515

Revision 0

Recommendation 6: VI-A. Add a statement defining the desired and necessary degree of interaction with, and complementary roles of, industry and NRC to this Program.

Recommendation 7: VI-B. A MOU explicitly defining the relative roles of DOE versus industry for LWRS R\&D needs to be executed. The role of NRC is quite well articulated already.

Page: 22

Specific Related Steering Committee Observations and Page:

Resolution: Agree with recommendation.

- $\quad$ An MOU with NRC already exists. A DOE MOU with EPRI will be developed in June 2010 before the next Steering Committee meeting to address the appropriate roles of DOE versus industry for LWRS R\&D needs.

- A Stakeholder Engagement Plan is being developed to supplement the MOU. This plan will be issued after the MOU is completed. 
INL/EXT-09-17515

Revision 0

Recommendation 8: VII-A. The committee recommends that TIO take the appropriate action necessary to achieve establishment of the Program as a national need, development of a longterm profile for the Program, development of Program task criteria, and outreach to nontraditional R\&D performers in needed specific areas.

Page: 23

\section{Recommendation 9:}

VIII-A. Criteria for prioritization of tasks judged suitable within the LWRS Program:

No written criteria were presented to the Advisory Committee. The Committee suggests consideration of the following set listed in priority order by the TIO as it develops its recommended set of criteria:

1. Delivery of Results by, say 2013 (date to be established by the TIO) which are essential for industry to conclude that it is prudent to proceed to prepare an application for the license for operation beyond 60 years above and support life-cycle management decisions on long term operation.

2. Delivery of Results by, say 2019 (dates to be established by the TIO) which are essential to support continued operation through the 80-year license period achieved through step 1 above.

3. Delivery of Results in the 2013 - 2019 timeframe (dates to be established by the TIO) supporting incremental capacity addition and for significant modernization/refurbishment.

Generally applying these four criteria above for prioritization of work proposed would give a funding priority on pathway basis of NMAD, ANF, IIC, and RISMC.

Page: 24

\section{Specific Related Steering Committee Observations and Page:}

Resolution: Agree generally with recommendations and have implemented them as follows:

- The LWRS Program has been branded as a national priority by the recent DOE-NE R\&D roadmap. Imperative 1 of that roadmap is to "extend life, improve performance, and maintain safety of the current fleet."

- $\quad$ The revision 2 of the Program Plan (issued in December 2009) has developed a 20-year profile of the LWRS Program. Program level criteria also have been established to drive achievement of program goals. TIO also is developing a Stakeholder Engagement Plan to engage the entire nuclear energy community, including outreach to nontraditional R\&D performers in needed specific areas. The Stakeholder Engagement Plan will include publication and communication plans to raise awareness and increase the prominence of the program. The plan will be issued in June 2010. 
INL/EXT-09-17515

Revision 0

- We have established program level criteria addressing work scope relative to program goals, need dates, and that the work is consistent with the role of DOE. Program level criteria are as follows:

- $\quad$ Scope of work: Is the work an essential or important part of reaching the following Program goals: (1) safety and licensing for long-term operations, and (2) reliability and economics for long-term operations?

- $\quad$ Role of federal funding: Does the work require a unique capability of DOE (including laboratories and university collaborators) or for other reasons it will not be done if left to the industry alone? Usually this is long-term, high-risk work that may require expertise or infrastructure at DOE laboratories to establish the scientific underpinning with industrial or regulatory collaboration to apply it.

- $\quad$ Timeliness: Does the work meet goals for Phases I, II, III, and IV as laid out in the revision 2 of the LWRS Program Plan (shown below)?

\begin{tabular}{|c|c|c|c|c|c|}
\hline & Phase I & Phase II & \multicolumn{2}{|c|}{ Phase III } & Phase IV \\
\hline & $\begin{array}{l}\text { Building Confidence in } \\
\text { Life Extension with } \\
\text { Data and Tools }\end{array}$ & $\begin{array}{l}\text { Enable Industry Decision } \\
\text { to Invest and License } \\
\text { for Life Extension }\end{array}$ & \multicolumn{2}{|c|}{$\begin{array}{l}\text { Applications of Scientific Solutions to Address } \\
\text { Issues in Life Extension Decision Making and } \\
\text { Continuing Technology Development }\end{array}$} & \multirow{17}{*}{$\begin{array}{l}\text { Licensed } \\
\text { Operations } \\
\text { for } 80 \text { Year } \\
\text { Life Extension }\end{array}$} \\
\hline \multirow{3}{*}{ Materials } & $\begin{array}{l}\text { Key materials data and } \\
\text { mechanistic understanding } \\
\text { for key degradation modes }\end{array}$ & $\begin{array}{c}\text { Comprehensive materials } \\
\text { data and methods available }\end{array}$ & \multicolumn{2}{|c|}{ Support the NRC and applicants with data and methods } & \\
\hline & \begin{tabular}{|c|} 
Status and action plan \\
for lifetime prediction models \\
for key components and \\
degradation modes
\end{tabular} & $\begin{array}{l}\text { Development of lifetime } \\
\text { performance models }\end{array}$ & $\begin{array}{l}\text { Validation of lifetime } \\
\text { performance models }\end{array}$ & $\begin{array}{c}\text { Implement lifetime } \\
\text { performance models via } \\
\text { Proactive Materials } \\
\text { Degradation Management } \\
\end{array}$ & \\
\hline & $\begin{array}{l}\text { Development of } \\
\text { mitigation tools and } \\
\text { advanced materials }\end{array}$ & $\begin{array}{c}\text { Development of } \\
\text { mitigation strategies } \\
\text { and advanced materials }\end{array}$ & $\begin{array}{c}\text { Validation of } \\
\text { mitigation strategies } \\
\text { and advanced materials }\end{array}$ & $\begin{array}{c}\text { Implementation of } \\
\text { mitigation strategies } \\
\text { and advanced materials }\end{array}$ & \\
\hline \multirow{3}{*}{ Fuels } & $\begin{array}{l}\text { Advanced fuel key feature } \\
\text { test data }\end{array}$ & & & & \\
\hline & $\begin{array}{l}\text { Lead test rod with } \\
\text { advanced cladding }\end{array}$ & $\begin{array}{l}\text { Lead test assembly } \\
\text { with advanced cladding }\end{array}$ & $\begin{array}{c}\text { Initial core reload } \\
\text { with advanced cladding }\end{array}$ & $\begin{array}{c}\text { Implementation of advanced } \\
\text { cladding and advanced } \\
\text { fuel designs underway }\end{array}$ & \\
\hline & \begin{tabular}{|c|} 
PSAR for advanced cladding \\
in a real LWR environment \\
\end{tabular} & & & & \\
\hline \multirow{3}{*}{$118 \mathrm{C}$} & $\begin{array}{l}\text { Pilot demonstration of } \\
\text { online monitoring installed } \\
\text { in a commercial plant }\end{array}$ & $\begin{array}{l}\text { Fleet-wide testing } \\
\text { of online monitoring }\end{array}$ & \multicolumn{2}{|c|}{ Application of online monitoring } & \\
\hline & \begin{tabular}{|c|} 
Testing of advanced II\&C \\
modernizations by industry \\
in reconfigurable control lab \\
\end{tabular} & $\begin{array}{l}\text { Accepted modernization } \\
\text { strategy for II\&C }\end{array}$ & \multicolumn{2}{|c|}{ Implementation of modernized II\&C } & \\
\hline & \begin{tabular}{|c|} 
Development underway of \\
next generation, on line NDE
\end{tabular} & $\begin{array}{c}\text { Testing of next generation } \\
\text { on line NDE }\end{array}$ & \multicolumn{2}{|c|}{ Application of next generation NDE technologies } & \\
\hline \multirow[b]{2}{*}{ RISMC } & \begin{tabular}{|c|}
$\begin{array}{c}\text { Development of R7 code } \\
\text { (beta version release 2015) }\end{array}$ \\
\end{tabular} & $\begin{array}{l}\mathrm{R} 7 \text { code testing, } \\
\text { demo, and validation }\end{array}$ & \multirow{2}{*}{$\begin{array}{l}\text { Validation of } \\
\text { RISMC methods and tools }\end{array}$} & \multirow[b]{2}{*}{$\begin{array}{l}\text { Implementation of } \\
\text { RISMC methods and tools }\end{array}$} & \\
\hline & $\begin{array}{l}\text { Development of } \\
\text { RISMC framework }\end{array}$ & $\begin{array}{l}\text { RISMC framework } \\
\text { advances and } \\
\text { demonstration }\end{array}$ & & & \\
\hline \multirow{4}{*}{$\begin{array}{l}\text { Economics } \\
\text { \& Efficiency }\end{array}$} & & & & & \\
\hline & $\begin{array}{l}\text { Preserve once-through } \\
\text { cooling technology }\end{array}$ & \begin{tabular}{|l|} 
Cost reduction and \\
efficiency improvement of dry \\
and hybrid cooling technology
\end{tabular} & \multicolumn{2}{|c|}{ Application of advanced cooling technologies } & \\
\hline & $\begin{array}{l}\text { Water conservation } \\
\text { technologies for } \\
\text { wet cooling towers }\end{array}$ & & & & \\
\hline & \multicolumn{4}{|c|}{ Enable $10 \mathrm{GWe}$ extra capacity addition through power uprates, with a stretch goal of $20 \mathrm{GWe}$} & \\
\hline & & & & & \\
\hline
\end{tabular}

- $\quad$ Program objectives drive pathway prioritizations and establishment of pathway milestones. The FY 2010 work scope includes the work packages for planned R\&D and further 
INL/EXT-09-17515

Revision 0

planning work to complete the program planning process. As we stand now, program planning is still evolving. We plan to have the integrated priority list of R\&D tasks ready for FY 2011, similar to how we manage other more mature DOE NE programs like NGNP. Specific criteria for project selection and prioritization of tasks are established in the following:

a. The project must address a practical problem:

(1) The project leads to a defined outcome that has practical benefits to the sustained operation of existing LWRs.

(2) The project need has been defined in a documented gap analysis or similar evaluation.

b. The project must be coordinated with other stakeholders;

(1) Planned activities must be coordinated with other stakeholders to avoid duplication and ensure synergies are achieved. The primary stakeholders include related or similar DOE/national laboratory R\&D activities, NRC, EPRI, INPO, and U.S. nuclear utilities. Other stakeholders could include the Nuclear Energy Institute, various U.S. companies (vendors), and numerous international organizations, including IAEA and NEA.

(2) Use of cost share arrangements must be evaluated and employed to the maximum extent possible to leverage the use of federal funds.

c. The project must use a science-based approach, replacing empirical methods with more fundamental science-based methods for design and safety evaluation tools. A science-based approach employs the following:

(1) Experiments - Physical tests done to extend data and understanding of single effects or integrated system behaviors.

(2) Theory - Creation of models (i.e., theories) of physical behaviors based on understanding of fundamental scientific principles or experimental observations and data.

(3) Modeling and simulation - Use of quantitative models integrating both theory and experiment to develop and apply scientific understanding of physical behaviors of complex systems.

(4) Demonstrations - New technologies, regulatory frameworks, and business models integrated into first-of-a-kind system demonstrations that provide top-level validation of integrated system technical and financial performance. 
INL/EXT-09-17515

Revision 0

\section{Recommendation 10:}

IX-A. As budget uncertainty resolves, the TIO program function should accelerate its efforts to put solid program management tools in place to drive the program.

Page: 26

\section{Specific Related Steering Committee Observations and Page:}

The program does not have sufficient program management tools in place to drive the program. These include developing criteria for project selection, prioritization and funding; developing, coordinating and driving synergies among the pathways; and, setting pathway/project targets (milestones and products) that drive program goals such that there is adequate assurance that the efforts will lead to products of timely value to the industry. Page 25

Resolution: Disagree with recommendation. Solid project management tools are in place consistent with funding levels and uncertainties as follows:

- $\quad$ Project management tools - The project uses traditional project controls that include defining a work breakdown structure, establishing performance baselines (scope, schedule, and budget), performance baseline measurements, baseline change control, and reporting project status. In addition to using INL work and project management procedures, the LWRS R\&D Program will develop a risk management plan, software quality assurance plan, records management plan, data management plan, and training plan to govern how program activities will be conducted.

- $\quad$ Project management processes - Preliminary draft funding guidance is provided by DOE-NE. Based on this guidance the LWRS R\&D program director, program manager, control account managers and work package managers develop an annual Integrated Priority List (to be developed). Based on this priority list, the director assigns scope and an estimated budget to the control account managers. Each control account manager then develops a control account plan. Control account plans and work packages are submitted to the LWRS R\&D program director and program manager for review and approval.

Consistent with the agreed upon budget and associated scope, DOE-NE issues an annual program execution guidance letter to DOE-ID authorizing the scope and funding to be issued to INL. INL work packages, basis of estimates, and control account plans are revised as required using the baseline change control process.

- $\quad$ Organization structure - The entire LWRS R\&D Program falls within the DOE-NE. Program management and oversight, including programmatic direction, project execution controls, budgetary controls, and TIO performance oversight is provided by the DOE Office of LWR Deployment (DOE-HQ) in conjunction with the DOE Idaho Operations Office (DOE-ID). 
INL/EXT-09-17515

Revision 0

The TIO basic organizational structure is used to accommodate the crosscutting nature of the proposed research pathways. This organization is responsible for developing and implementing integrated research projects consistent within the LWRS R\&D Program vision and objectives.

Additional information may be found in the LWRS Program Plan, FY 2009-2013, INL/MIS-08-14918, Revision 2, December 2009. 
INL/EXT-09-17515

Revision 0

\section{Recommendation 11:}

IX-B. The performance criteria for selecting Pathway Leads should be established and implemented when new personnel selections become necessary.

Page: 26

\section{Specific Related Steering Committee Observations and Page:}

The role of the four R\&D Pathway leaders is critical to identifying suitable R\&D tasks which fit TIO criteria and R\&D performers to whom task performance is entrusted. These leaders need to be open to selection of R\&D tasks for DOE funding based on collaborative DOE/industry/NRC identification of LWRS needs and LWRS Program criteria, have knowledge of industry- and NRC-related LWRS programs that currently complement the DOE LWRS Program, have knowledge of $R \& D$ performers in the nuclear energy community, and have the willingness to seek out potential R\&D performers from other research communities who can bring fresh insight on research pathways specific selected tasks. Page 26

Resolution: Agree to document and formalize the criteria that had been used to select pathway leads.

- Pathway leads were selected by TIO with DOE consultation. They were selected based on qualifications, experience, and job functions:

- Pathway lead will be a recognized expert in the pathway technical area

- Education and experience in technical area of pathway

- Demonstrated communication ability - spoken and written with stakeholder community

- Demonstrated technical and administrative leadership.

A one page job description will be completed in June 2010. 
INL/EXT-09-17515

Revision 0

\section{Recommendation 12:}

$\mathrm{X}$-A. The TIO should establish a nominal 10 year plan encompassing existing reactors based upon refinement of the estimates above.

Page: 28

\section{Specific Related Steering Committee Observations and Page:}

We take 20 years as a first estimate of the minimum period of a LWRS Program and suggest next the cost and contribution structure for such a program although later under RECOMMENDATIONS we advise the TIO to develop a plan only for the first 10 years because of the difficulty of projecting beyond 10 years in this area at this time. Page 27

Resolution: We agree with developing a plan for only the first 10 years.

We currently have a 5-year plan, which is appropriate for the time and resources available for planning. In FY 2010, one top priority is to issue a 10-year program plan. 
INL/EXT-09-17515

Revision 0

\section{Recommendation 13:}

$\mathrm{X}-\mathrm{B}$. The TIO should execute the comparative ranking as discussed in X-B above using a clearly established set of criteria. We suggest the prioritized set of 4 criteria presented earlier in recommendation VIII-A.

Page: 29

\section{Specific Related Steering Committee Observations and Page:}

The required funding levels in each of the next 5 years depend on both the timing of the need of results for licensing and economic operation of the existing fleet. As already stated, these timing needs have not been established by the Program.

Resolution: Agree with recommendation.

- $\quad$ The planning and criteria established in the resolution to Recommendations 8 and 9 will provide the basis for funding prioritization.

- As it stands now, the program is still evolving and not yet mature enough. A comparative ranking table will be developed as the program gets more mature to address funding criteria.

- The current approach is that it is important to fund each pathway. Given the extreme importance of the nuclear material aging and degradation pathway and its possible technical impediment to long-term operation, a minimum $20 \%$ of the funding is dedicated to that pathway. The remaining pathways are about equally funded. 
INL/EXT-09-17515

Revision 0

\section{Recommendation 14:}

XI-A. Work in the area of fatigue should be considered to increase confidence in the estimates of environment on fatigue life and minimize the likelihood of unnecessary repairs and replacements or inspections.

\section{Page: 31}

\section{Specific Related Steering Committee Observations and Page:}

Fatigue is a cumulative aging damage mechanism that will become increasingly important as reactor life is extended. Although it was recognized as a factor in the original design of plants, the problem has been aggravated by the recognition that the initial estimates of fatigue life were based on the behavior of materials in air, and fatigue lives can be significantly decreased in LWR coolant environments. Although acceptable fatigue aging management programs have been developed for plants undergoing license renewal, these programs could involve inspection, repair, and replacement activities that are expensive and involve significant worker exposure to radiation. Past research by the industry and the NRC has lead to the developments of methods to estimate the effect of the environment on fatigue life. Page 30

Resolution: Agree with recommendation.

- $\quad$ Fatigue is an issue for life extension and was identified as a research need at the expert working group meeting. Fatigue and environmental fatigue were listed among the 39 tasks identified by the working group (described in more detail in the LWRS Program Plan). While this is an important mode of degradation, other forms were determined to be of higher priority. Current funding levels have only permitted research into six of the 39 tasks in FY 2010.

- $\quad$ Complementary research on creep and creep-fatigue issues is a part of the FCRD and GenIV programs. These research efforts are focusing on methodology issues that may be used for LWR life-extension considerations. This mode of degradation will continue to be assessed as part of the NRC PMDA activity and research may be initiated as more funding becomes available. 
INL/EXT-09-17515

Revision 0

\section{Recommendation 15:}

XI-B. Flow Accelerated corrosion phenomenon should be explored in a gap analysis. However, even if such an analysis identifies needed R\&D, the Committee is likely to disagree whether such work should be performed within the industry program or by the LWRS Program. A Committee debate on this question would be timely after the gap analysis has been performed.

Page: 31

\section{Specific Related Steering Committee Observations and Page:}

Flow accelerated corrosion (FAC) is a materials degradation phenomenon that has resulted in catastrophic piping failures at the Mihama plant in Japan and the Surry and Fort Calhoun plants in the US and led to casualties. Although replacement materials that are highly resistant to FAC are available and targeted inspection programs and other means of mitigation have been developed (e.g., more effective $\mathrm{pH}$ control agents), management of FAC currently requires fairly extensive inspection and replacement programs. The industry sees FAC as an asset management issue, and R\&D needs are being met by existing program activities. Page 31

\section{Resolution: Agree with recommendation.}

- $\quad$ There were many different modes of degradation considered by the expert working group. As with fatigue issues, flow-accelerated corrosion was identified as a research need for life-extension issues. While this is an important mode of degradation, other forms were determined to be of higher priority for the limited funding in the early years of the program. Further, as noted in the comment, this is an issue being actively researched by industry. While there are potential tasks that are distinct from industry and are DOE appropriate, these tasks are of lower priority.

- This mode of degradation will continue to be assessed as part of the NRC PMDA activity and research may be initiated if an appropriate need is identified and more funding becomes available. This will be accomplished via a white paper/gap analysis for buried piping that is planned for FY 2011 (or FY 2010 if additional funding is secured). 
INL/EXT-09-17515

Revision 0

\section{Recommendation 16:}

XI-C. A gap analysis should consider targeted work on Alloy 690 to explore its performance further in secondary side conditions and assure there are not significant degradation mechanisms that may show up at much longer times than we have achieved to date

Page: 32

\section{Specific Related Steering Committee Observations and Page:}

Alloy 690 secondary side service. Secondary side effects have been very important in the plants to date, because the water chemistry is less well-characterized than that on the primary side. Resin bed break-through, condenser leaks, and corrosion products provide sources of secondary side impurities. The generation of steam can lead to concentration factors of $10^{6}$ or more for these impurities in secondary side deposits. Alloy 690, the current steam generator tube material, is performing well in service and has been shown to be extremely resistant to stress corrosion cracking in primary water conditions, but is known to be susceptible to cracking in the presence of impurities such as $\mathrm{Pb}$ that are know to accumulate in secondary side deposits. Page 31

\section{Resolution: Agree with recommendation.}

- $\quad$ Research to understand and predict cracking in Ni-base alloys also was identified as a need to ensure safe and reliable operation during life extension. The expert working group (see the LWRS Program Plan for more information) determined this task was a high-priority need given the occurrence of cracking in today's LWR fleet and the likely effects of added time, stress, and exposure to coolant.

- However, many other research efforts around the world are currently in this area and identifying DOE-appropriate and independent research is more difficult. One key outstanding need is understanding precursor states and their influence on crack initiation and growth in Alloy 690. With this information, lifetime predictions and mitigation strategies can be identified, leading to greater reliability and support of modeling activities.

- This mechanistic research was initiated in the LWRS FY 2009 Program at PNNL, but halted in the early portion of FY 2010 due to limited funding and other Steering Committee guidance that too much work was focused on metals. This task will continue as soon as additional funding is allocated. This may be in FY 2010 if NEUP funding is released to the program.

- $\quad$ This mode of degradation also will continue to be assessed as part of the NRC PMDA activity and additional or refocused research may be initiated. 
INL/EXT-09-17515

Revision 0

\section{Recommendation 17:}

XI-D. Because of the extensive history of past effort on pressure vessel embrittlement, new effort should be focused on specific experiments and approaches that look particularly promising or could provide specific new insights. The DOE effort in this area should maintain cognizance of past efforts and consider their impacts on the research planned.

\section{Page: 33}

\section{Specific Related Steering Committee Observations and Page:}

The top priority tasks are the pressure vessel and IASCC tasks. However, the pressure vessel work is confirmatory rather than transformative. Based on what is known today, it is unlikely that pressure vessels will be life-limiting for 80 years. But confirmation is needed that our heavily empirical understanding can in fact be extrapolated to the extended life time. Further, the Committee discussed the adequacy of in-vessel samples to do the long term irradiation evaluation out to 80 years. There are industry efforts to assess and optimize the use of the available surveillance specimens that some LWRS Program work could complement. Page 32

\section{Resolution: Agree with recommendation}

- If there are no new mechanisms for radiation-induced changes in RPV steels, then it is indeed unlikely that RPV will be life limiting. However, past NRC and industry campaigns have led to predictions of high-fluence phase transformations (so-called "late blooming phases") that may not appear until fluences beyond a 60-year lifetime. Such phases have been observed in the very early parts of this program. Indeed, the initial high-fluence specimens examined have exhibited hardening well above the current NRC predictions (IVAR). This indicates that RPV embrittlement may indeed be life-limiting and more research is needed to evaluate the impacts of high-fluence effects on RPV steels. EPRI and NRC have both identified this as a key need, but have not initiated research in this area.

- LWRS-led research is focused on understanding mechanisms and not merely generation of data (although this is important too). Controlled-composition specimens, modern analytical techniques, and computation insights are all being employed to help identify future research needs and provide fundamental information.

- As data and the scope of the potential issue under extended service become more clear, more refined end-goals and timelines will be developed. If, for example, RPV embrittlement is not an issue, this task can be completed and resources moved to other high priority needs. However, if embrittlement is found to be a concern for license extension, additional research will be required to identify possible operational limits. Objective criteria and decision points will be identified by mid-FY 2010 (March 30, 2010).

- $\quad$ Future research tasks for validating high-flux or surrogate material techniques (which will be required due to limited coupons available in plants today) have already been identified and will be initiated as more funding becomes available. 
INL/EXT-09-17515

Revision 0

\section{Recommendation 18:}

XI-E. Because of the extensive history of past effort on IASCC \& weldments, new effort should be focused on specific experiments and approaches that look particularly promising or could provide specific new insights.

Page: 33

\section{Specific Related Steering Committee Observations and Page:}

The work on IASCC is more transformative. The fundamental mechanisms of IASCC are not yet understood and this phenomenon has not yet been adequately addressed even for life up to 60 years.

The third priority is the weldment task, which focuses on experimental measurements of welding residual stress to permit better validation of analytical models. It is less critical to licensing than the vessel and IASCC tasks are, but it is transformative because of the role it can play for reactor internals refurbishment and replacement. Page 32

Resolution: Agree with recommendation.

- As noted by Steering Committee comments, the fundamental mechanisms of IASCC are not known. DOE-led work in this area will be focused on the underlying mechanisms and provide fundamental knowledge by using a series of single-variable conditions and improved analytical techniques.

- $\quad$ Research into weldments also has been initiated in FY 2010. As noted above, this is less critical than RPV or IASCC tasks, but it is more transformational in nature. The DOE-led research is focusing on understanding the influence of residual stress on crack initiation of weldments. Research will use both characterization and modeling and is oriented toward fundamental mechanisms. In addition, advanced joining techniques for weld-repair also will be examined. This may offer a mitigation strategy for cracking beyond component replacement and could transform management of primary and secondary component management.

- Specific deliverables and milestones for these two tasks are listed in the Program Plan. 
INL/EXT-09-17515

Revision 0

\section{Recommendation 19:}

XI-F. Efforts to identify candidate DOE funded tasks should be pursued particularly by interaction with non-traditional reactor technology specialists, especially in relation to concrete, cable and buried piping.

Page: 33

\section{Specific Related Steering Committee Observations and Page:}

As important as the concrete, buried piping and cable tasks are to licensing, suitable sciencebased DOE efforts are not yet identified in what has been proposed. Page 32

Resolution: Agree with recommendation.

- $\quad$ Understanding the potential impact of degradation of concrete, cabling, or buried piping will be important when considering further life-extension decisions.

- $\quad$ Concrete was identified as a high-priority need by the expert working group due to the lack of information on concrete performance. Further, the significant difficulties associated with concrete replacement may make this a life-limiting issue. The research identified in this area is part of a larger, collaborative, and science-based approach combining characterization and service experience to provide a framework for predictive capability.

- Cabling and buried piping also are important and have been identified as high-priority needs (although funding has been limited). In each area, a first step will be to provide a detailed analysis to assess key degradation modes of today, key degradation modes for extended service, research needs, ongoing research by industry and regulatory bodies, and ultimately identify DOE-appropriate research (if any). This analysis will be initiated in FY 2010 for cabling. The buried piping assessment will be initiated as funding becomes available.

- In all areas, nonreactor expertise will be engaged. For example, in concrete, civil engineering expertise and experience will be vital for timely and efficient research. Department of Transportation databases on bridge and highway reliability are one specific example resource that has been engaged by the LWRS Program.

- $\quad$ These modes of degradation will continue to be assessed as part of the NRC PMDA activity and additional or refocused research may be initiated.

- As data and scope of the potential issue under extended service become more clear, more refined end-goals and timelines will be developed. If concrete degradation is found to not be an issue, this task can be completed and resources moved to other high priority needs. However, if concrete failures are found to be a concern for license extension, additional research will be required to identify possible operational limits. Objective criteria and decision points will be identified by mid-FY 2010 (March 30, 2010). 
INL/EXT-09-17515

Revision 0

\section{Recommendation 20:}

XI-G. The components which are critical for safety should be identified ab initio and monitored continuously over their period of operation. Monitoring and inspection technologies need to be further developed in conjunction with the IIC Pathway.

Page: 33

\section{Specific Related Steering Committee Observations and Page:}

An effective surveillance program for components critical for safety is a must and any effective approaches for that purpose (e.g. NDE, sensors, information evaluation, etc) should be encouraged. Predictive methods for aging and degradation would be very helpful in identifying possible locations of degradation and damage before it occurs, resulting in a more focused inspection and equipment replacement program. Page 33

Resolution: Agree with recommendation.

- This is clearly an area of collaboration between pathways. This was identified early in planning for the program, but has not been initiated due to lack of dedicated funding. It is envisioned that sensors and tools developed will be validated in concert with testing in the materials pathway. For example, if a new sensor is developed for concrete analysis, that sensor can be tested and benchmarked during the ongoing testing campaign. This approach will improve collaboration and potentially provide a tool that is validated for use in a shorter timeframe.

- Monitoring and surveillance technologies will be very important for plant and component management. This was identified as a key area of research in LWRS as it is potentially transformational. Online or NDE evaluations of key components will greatly reduce uncertainty in performance and safety margins. For example, if a technique (such as ultrasonic) can be developed to monitor the integrity of concrete structures, it may replace costly and destructive core drilling (which also suffers from the potential of giving a localized and not representative result). RPV and concrete NDE techniques will be given the highest priority, as this is very complementary to other ongoing research. However, limited funding has delayed initiation or further exploration of this effort.

- $\quad$ NDE and surveillance techniques also were listed as a key area of interest in recent SBIR calls.

- $\quad$ NDE activities planned under the II\&C pathway this year focus on analysis of needs, assessment of capabilities, and gaps that exist between needs and capabilities that can be addressed through $\mathrm{R} \& \mathrm{D}$. Workshops and meetings are planned in the II\&C pathway to support development of the information and assessments needed to coordinate activities with the NMAD pathway and to formulate a plan and budget of prioritized activities in this pathway in out years. 
INL/EXT-09-17515

Revision 0

\section{Recommendation 21:}

XII-A. The strategically most important objectives noted earlier must be preserved to the extent possible by the reduced funding alternative.

Page: 43

\section{Specific Related Steering Committee Observations and Page:}

Emphasis on Analytic versus Experimental Tasks - We conclude that there is too much emphasis on analytical tasks and too little emphasis on experimental tasks and this is made worse in the proposed changes for the reduced funding case.--------------. Page 41

Resolution: Agree with recommendation.

- $\quad$ Balance analytic and developmental activities with additional emphasis on designing prototype rods and irradiation campaigns. Changes were made in the FY 2010 program to address the comment. Analytic activities were reduced and multiple direct irradiation plan and design activities were emphasized.

- $\quad$ The strategic program will include feedback from vendors and industry in FY 2010 and will incorporate major milestone of FY 2010 in the strategic plan for September 2010. 
INL/EXT-09-17515

Revision 0

\section{Recommendation 22:}

XII-B. Since fuel vendor participation in cost sharing of the R\&D in this Pathway is highly desirable, the status and plans to enhance such vendor participation needs to be more explicitly discussed.

Page: 43

\section{Specific Related Steering Committee Observations and Page:}

Resolution: Agree with recommendation.

- $\quad$ TIO is developing a stakeholder engagement plan that will include vendor and industry engagement activities.

- Fuels activities will involve direct interaction with vendors to directly survey needs of each vendor. The intent is to find places where research will provide the best near-term benefit in speeding development of advanced nuclear fuel, providing benefit to the LWR sustainability decision, and improving current fuel performance. Interactions with vendors were started at the advance fuel cycle meeting on November 30, 2009.

- $\quad$ The advanced nuclear fuels pathway will be working more directly with EPRI on safety evaluation, $\mathrm{HAZOP}^{1}$ evaluation, and irradiation planning campaign, gaining the benefit of their utility perspective. EPRI provided an invitation to attend the EPRI/industry nuclear fuel operation meeting held February 22 through 26 to increase interaction with utilities.

- $\quad$ EPRI and vendor interactions are ongoing on the safety case, economic evaluation, fuel modeling, and program goals. These research and planning activities require increased vendor interactions.

\footnotetext{
${ }^{1}$ (HAZOP refers to a hazard and operability study that is a structured and systematic examination of a planned or existing process or operation in order to identify and evaluate problems that may represent risks to personnel or equipment, or prevent efficient operation.)
} 
INL/EXT-09-17515

Revision 0

\section{Recommendation 23:}

XII-C. A limited analytical approach based on reassessing available resources and data needs should be undertaken. The result should be the balanced analytical and experimental strategy called for by our comments.

Page: 43

\section{Specific Related Steering Committee Observations and Page:}

It would be more prudent to trim activities from the analysis tasks to free enough money for a well-defined, core set of experimental results for methods validation and code validation. This might need to include more explicit arrangements for access to Halden data and to seek data from the vendors for use in code validation. --------page 41

Resolution: Agree with recommendation.

- A primary task in FY 2010 is the start of a licensing basis for the SiC/SiCf (silicon carbide fiber) nuclear fuel. A HAZOP analysis will be jointly conducted with the RISMC pathway to evaluate $\mathrm{SiC} / \mathrm{SiCf}$ safety performance. The evaluation will provide a plant wide safety evaluation for the new fuel type and provide a needed gap analysis of current licensing unknowns. The gap analysis will allow a focus on specific experiments and analytic tools needed. The results will be provided in the FY 2010 strategic plan.

- The need to define the program around a specific development process is central to the research pathway. Using the required licensing information as a basis for required data collection will allow an efficient research program.

- $\quad$ The work package for the licensing basis case has been developed. Work on the cross cutting HAZOP with the RISMC pathway was started in November 2009. 
INL/EXT-09-17515

Revision 0

\section{Recommendation 24:}

XII-D. The SiC cladding development program should be structured to ensure its support by industry. There should be a single strategic plan for a 10-year $\mathrm{SiC}$ deployment target with appropriate parties funding specific tasks.

Page: 43

\section{Specific Related Steering Committee Observations and Page:}

SiC Cladding Development and Deployment. SiC cladding is the one true breakthrough technology under consideration in the LWRS Advanced Fuel Program and deserves greater priority and financial support. Further it has support of the plant owner/operators and vendors. However, the 10-year deployment time is critical. Utility advisors and fuel vendors indicate that they will not support $\mathrm{SiC}$ licensing and deployment unless it can be deployed in this timeframe. --------- page42

Resolution: Agree with recommendation.

- The vendors, DOE, and TIO started meetings in September 2009. The initial meeting has led to further discussions on coordinating industry and DOE research programs in November 2009. The current plan is to start sharing information in technical review meetings and perform additional planning. This will lead to a coordinated irradiation campaign and input on the licensing basis evaluation in FY 2010.

- The strategic planning tasks of the advanced nuclear fuel pathway will further include the needs of all nuclear fuel vendors, GE, and AREVA not currently involved in $\mathrm{SiC} / \mathrm{SiCf}$ research. These interests will be included in the 10-year strategic plan produced at the end of FY 2010.

- Coordination work with vendors has started on establishing research positions and priorities. Initial proposals for irradiation programs will be exchanged in 2010. Work on multiple research work packages for sample irradiation, design tasks, and safety evaluations has started on $\mathrm{SiC} / \mathrm{SiCf}$ that will require vendor interaction. 
INL/EXT-09-17515

Revision 0

\section{Recommendation 25:}

XII-E. Potential R\&D work on the mechanisms currently responsible for most of the fuel pin failures in the current fleet should be explored. The characteristics of the associated modeling effort that should be evaluated include:

1. A heavier emphasis on understanding the fundamentals of and modeling of the important larger-scale phenomena than on modeling at microscopic or meso-scale. Specifically greatly improved and more detailed models of a) the gradual property change associated with radiation effects on key mechanical components such as grid fingers (little springs), b) fluid structure interactions, and c) fretting and wear damage and the like, are needed;

2. Bundle scale flow-induced vibration simulation models that can be used to do the rapid prototyping needed in this area and replace the current highly empirical approach that has often gone astray;

3. A far more capable, robust and larger-scale analysis package than any currently available which supports and guides design to account for the mechanical and fluid hydraulic forces in fuel. This capability is needed in place of multi-bundle tests which are generally not economic or even possible.------------ Not all members of the Committee currently agree that this type R\&D work should be undertaken in the LWRS Program with a focus on existing fuel reliability issues since the industry activities are likely sufficient. Those members favor a focus on future design and analysis needs.

Page: $43 / 44$

\section{Specific Related Steering Committee Observations and Page:}

EPRI data show that the great majority of fuel rod failures in the present plants are initiated on the outside surface of the cladding and are typically associated primarily with fretting and flow vibration issues, the effects of debris and crud-clad interactions. Crud effects also lead to the axial offset anomaly. Fuel assembly/channel bowing and growth are also issues as evidenced by recent removal of MOX test assemblies from a commercial plant due to unexpectedly high growth. These issues may be complicated by the higher lift-off forces and balancing higher holddown forces that will be used in the higher power density and higher coolant flows of new reactor cores coming on line.

EPRI data show that the great majority of fuel rod failures in the present plants are initiated on the outside surface of the cladding and are typically associated primarily with fretting and flow vibration issues, the effects of debris and crud-clad interactions. Crud effects also lead to the axial offset anomaly. Fuel assembly/channel bowing and growth are also issues as evidenced by recent removal of MOX test assemblies from a commercial plant due to unexpectedly high growth. These issues may be complicated by the higher lift-off forces and balancing higher holddown forces that will be used in the higher power density and higher coolant flows of new reactor cores coming on line. 
INL/EXT-09-17515

Revision 0

Resolution: Agree with recommendation.

- Currently, the near-term issues of fretting and debris are not a focus of the DOE program. Initial model efforts are being made as part of the larger non-LWRS DOE nuclear fuel activities.

- Planned research on $\mathrm{SiC} / \mathrm{SiCf}$ and $\mathrm{SiC}$ thin film coatings on zirconium cladding will help address both the fretting and debris issue because of the high hardness of the material. The high hardness may cause other problems that need to be solved.

- These effects from flow vibrations will be addressed as part of SiC/SiCf program. The general modeling and experimental program will be available for use in zirconium systems.

- Development of the FY 2010 strategic plan will include vendor, utility, and EPRI inputs. If there is significant input from these sources that conventional cladding issues need to address, more focus will be placed on their resolution.

- Work packages and initial work has begun on the FY 2010 program to support the strategic planning milestone in FY2010. 
INL/EXT-09-17515

Revision 0

\section{Recommendation 26:}

XII-F. Consider maintaining a technical team from EPRI, NRC, INL, vendors, and other collaborators to determine these critical issues and advise on the core set of capabilities and validation data needed as the work in this Pathway proceeds.

Page: 44

\section{Specific Related Steering Committee Observations and Page:}

Resolution: Agree with recommendation.

- $\quad$ This process has started with vendors who have direct interest in SiC/SiCf development. The initial meeting was in September 2009, with follow on discussions occurring thereafter. Further meetings are being planned. The intent is to work toward a planning and technical sharing working team in FY 2010.

- A separate NRC interaction may be required to best facilitate the progress of the program.

- $\quad$ Planning and coordinating activities are underway. Further vendor and industry involvement will be added in February 2010 at the EPRI fuel meeting and by June 2010 as part of the licensing evaluation. 
INL/EXT-09-17515

Revision 0

\section{Recommendation 27:}

XII-G. The development of fuel assemblies with $\mathrm{SiC}$ clad fuel rods cladding should be given priority status in this Pathway. Tasks 3.2 and 3.3 investigate the analytical modeling and experimental data development for $\mathrm{SiC}$ cladding respectively. Neither is funded under the reduced plan.

Page: 45

\section{Specific Related Steering Committee Observations and Page:}

SiC Cladding Development and Deployment. SiC cladding is the one true breakthrough technology under consideration in the LWRS Advanced Fuel Program and deserves greater priority and financial support. ------------------------ Page 42

Resolution: Agree with recommendation.

Both activities were funded in refocused work packages to support the strategic planning milestone in September 2010 for FY 2010. 
INL/EXT-09-17515

Revision 0

\section{Recommendation 28:}

XII-H. Support a limited, enhanced analytical capability and a well-defined, core set of experimental results that can deliver a validated tool in 5 years and contribute to deployed fuel improvements in 10 years.

Page: 45

\section{Specific Related Steering Committee Observations and Page:}

Related to recommendation XIIC page 43, XIIG page 45, and observations: --------- It would be more prudent to trim activities from the analysis tasks to free enough money for a well-defined, core set of experimental results for methods validation and code validation. This might need to include more explicit arrangements for access to Halden data and to seek data from the vendors for use in code validation.--------page 41

Resolution: Disagree with recommendation. Agree with the concept but it is beyond the scope of the current program.

- Current vendor comments suggest that development of completed computer codes are not desired. Correlations that describe nuclear fuel performance are desired. The program goal may eventually center on advancing the existing fuel performance codes like Falcon and FRAPCON.

- $\quad$ Refocusing of the current plan intends to center on implementing SiC/SiCf prototype fuel. Supporting information required to design and model the fuel will be validated as required. The information required for licensing will be demonstrated through experiment.

- Forward development of specific code components will be defined in the strategic plan in September 2010.

- $\quad$ Strategic planning is underway for a licensing basis study for SiC/SiCf nuclear clad fuel in September 2010. 
INL/EXT-09-17515

Revision 0

\section{Recommendation 29:}

XII-I. The scope of work in the fuel design area should include assessment of new work at bundle and rod scale to address the key phenomena that are currently the leading causes of fuel failures and problems such as large-scale dimensional changes, fluid-structure interactions, vibration and fretting, leading long term to computer based flow vibration testing and, on a lesser priority, an enhanced understanding of clad-crud chemistry to elucidate the major effects and parameters. While these areas are being addressed now at a level satisfactory to industry, the emerging DOE science-based R\&D approach offers the potential to identify and investigate new and fundamental solution approaches. Such approaches should have application to both existing and new fuel designs expected for future operation in current plants.

Page: 45

\section{Specific Related Steering Committee Observations and Page:}

Resolution: Disagree with recommendation; however, agree with potential benefit but will follow active industry progress rather than program scope.

- Currently, the near-term issues of fretting and debris are not a focus of the DOE program. Initial model efforts are being made as part of the larger non-LWRS DOE nuclear fuel activities.

- Development of the FY 2010 strategic plan will include vendor, utility, and EPRI inputs. If there is significant input from these sources that conventional cladding issues need address, more focus will be placed on their resolution.

- DOE should work to provide science-based knowledge of critical benefit to the entire industry. Industry and DOE should work to identify critical issues where the benefit will be highest. The application of DOE resources to operational issues is not likely to be an efficient use of resources.

- Work packages and work has been started to support milestones of the FY 2010 program. 
INL/EXT-09-17515

Revision 0

\section{Recommendation 30:}

XII-J. (for reduced funding) Reduce the funding on analytical tasks. Decrease the large budgets in Tasks 2.1, 2.2, and 2.4; perhaps resulting in a less robust analytical tool. Consider deferring Task 2.3 which seems to be more useful for chemistry optimization studies or failure analysis. It does not seem directed toward optimization of design, validation, and deployment; which is the primary objective of the other work in the pathway that is funded in the reduced funding plan. Also, reconsider some aspects of Task 3.5, Advanced Mathematical Tools, in the reduced funding plan as part of Task 3.1, Design and Safety Analysis Tool.

Page: 46

\section{Specific Related Steering Committee Observations and Page:}

See background on similar to recommendation XIIH.

Resolution: Agree with recommendation.

- $\quad$ Stretching out funding for mechanistic modeling tasks, 2.1, 2.2, and 2.4 will allow other information to be created and allow ongoing verification of the created data. The lower funding level also will reduce the personnel requirements that make staffing simple.

- Section 2.3, Coolant Crud Chemistry, will be deferred until it can be coordinated with other DOE programs or until significant industry interest drives a response. This is similar to other near-term issues like fretting and debris failures.

- $\quad$ The Advanced Mathematical Tools 3.5 will be funded in out years as part of the refocusing effort. Final details will be defined in the strategic planning activity.

- $\quad$ Currently, changes have been made for FY 2010; strategic changes will be made going forward based on further program input. 
INL/EXT-09-17515

Revision 0

\section{Recommendation 31:}

XII-K. (For reduced funding) Define and fund a specific core set of experimental results to validate the reduced scope analytical capability above. Address likely, specific future needs of existing reactors that can be delivered within 10 years. Reduce priority on reliability issues that are being adequately managed for current fuel designs and on more speculative fuel designs, power levels, or very high burn-up fuels. Re-instate necessary funding for Tasks 1.3 and 3.4 to support this experimental campaign.

Page: 47

\section{Specific Related Steering Committee Observations and Page:}

Resolution: Agree with recommendation.

- $\quad$ Both advanced nuclear fuels and TIO support Task 1.3, Halden Support, and are working toward resolution. Task 3.4 is being supported.

- $\quad$ Task 1.3 is being worked toward resolution with Halden. Task 3.4 is ongoing as best available until Task 1.3 is completed. 
INL/EXT-09-17515

Revision 0

\section{Recommendation 32:}

XII-L. Consider establishing a task group to specify what changes in the current deployment plan are necessary to expedite $\mathrm{SiC}$ implementation. The target deployment date should be 10 years or less. Fund Tasks 3.2 and 3.3 based on this assessment.

Page: 47

Specific Related Steering Committee Observations and Page:

Resolution: Agree with recommendation.

- The vendors, DOE, and TIO started meetings in September 2009. The initial meeting has led to further discussions on coordinating industry and DOE research programs. The current plan is to start sharing information in technical review meetings and perform additional planning. This will lead to further coordinated FY 2011 research.

- Strategic planning tasks of the advanced nuclear fuel pathway will further include the needs of all nuclear fuel vendors encouraging those not currently involved in SiC/SiCf research.

- $\quad$ Coordination work with vendors has started. Work on multiple research work packages has started on $\mathrm{SiC} / \mathrm{SiCf}$ that will require vendor interaction.

- $\quad$ Tasks 3.2, Mechanical Models of Composite Cladding, and 3.3, Irradiation Design Studies of Advanced SiC Cladding, are being funded. 
INL/EXT-09-17515

Revision 0

\section{Recommendation 33:}

XII-M. Re-consider the priority of Task 2.5, Hydrogen Uptake of Zr Cladding, with input from EPRI and NRC.

Page: 47

Specific Related Steering Committee Observations and Page:

Resolution: Agree with recommendation.

- $\quad$ Task 2.5, Hydrogen Uptake of Zr Cladding, will be evaluated with input from EPRI and NRC. It is anticipated that university programs will support hydrogen uptake in zirconium research.

- $\quad$ Research will be evaluated in strategic planning in FY 2010. University programs are anticipated to provide research into hydrogen uptake in zirconium research. 
INL/EXT-09-17515

Revision 0

\section{Recommendation 34:}

XIII.A. Assessment of R\&D Needs. A careful analysis of needs for 60 to 80 year license extension should first be performed. This analysis should be based upon a structured data and issues process which consists of the following steps:

1. Develop an initial inventory of key IIC path issues affecting further license extension to eighty years

2. Identify associated plant inspection or monitoring activities that are needed but not already in progress

3. Identify additional IIC path aging mechanisms that need to be accounted for in extending the license another twenty years that are:

a. Applicable to IIC path equipment and systems including electrical equipment that may not need to be replaced to achieve 60 to 80 year life extension, e.g., cables, and/or

b. Amenable to the use of improved IIC technology, e.g., in-situ monitoring of passive SSCs

4. Identify areas where new data is needed for IIC path equipment to extend known aging mechanisms or life expectancy data used in the current license extension process, e.g., electrical insulation

5. Identify areas where additional data is needed to make adequate estimates of effort and cost to extend the life of IIC path equipment for the life of the plant

6. To the degree practical, identify R\&D upon which early starts to support an additional twenty years of life extension could be initiated.

The results should be documented very quickly as part of the activity. The IIC Pathway team should then do a thorough, documented gap analysis, using the result of this data gathering process, other reports, interviews with experts, existing information, and the like to compare the identified IIC path needs for extending licenses from 60 to 80 years to ongoing efforts by industry, USNRC and the National Labs. The team should then use the gap analysis to plan the detailed IIC program and budgets based on plugging the gaps identified.

Page: 48

\section{Specific Related Steering Committee Observations and Page:}

Assessment of R\&D Needs. The four IIC pathway themes are appropriate for IIC work in support of LWR Sustainability. However, a careful analysis of the needs in this area for 60 to 80 year license extension has not been done, or if done, is not reflected in the planning and explanation of the tasks and themes selected to date. A plan to establish these needs is required 
INL/EXT-09-17515

Revision 0

which considers the results from past EPRI survey/review and the LWRS Program workshop on future IIC architecture and capabilities. This plan could be derived from conduct of a carefully structured process to collect data and issues, perhaps via a workshop or workshops with different participants to assure complete coverage, particularly gathering participants from several of the plants with the earliest end dates of their license extension to sixty years, the USNRC and other selected industry participants. This process could then be followed by a gap analysis to be used for planning the detailed IIC Program. Page 48

Resolution: Disagree with recommendation. The issue is not a "like-for-like" replacement of aging instruments, controls, and information systems with no change in staffing, methods of operation, maintenance, and management of nuclear power plants over the next 50 years. The issue is the vision and path to operating current fleet of nuclear power plants with next generation advanced II\&C technologies. This is what the industry wants as outlined in the LWR R\&D Strategic Plan and in the planning described below:

- Workshops with asset owners, vendors, research institutions, and international organizations are planned or have been held to identify the needs and a plan to address these needs for future II\&C architectures. In March 2009, a workshop was held at Ohio State University to address these issues for advanced information and automation technologies needed to address management of aging and long-term sustainability of II\&C systems at commercial nuclear power plants. Four utilities, comprising over 100 operating nuclear power plants, attended and participated in this R\&D needs identification and planning workshop. The emphasis of this workshop was on transformational technologies that will be needed to ensure that today's nuclear plants remain a viable and safe means of electricity production - and emphasized efforts in other countries and industries to achieve sustainable fleet wide technologies. At the time of the committee meeting, information from the Ohio State University workshop had not been reviewed and released. A report of this workshop is now available.

- Workshops also are planned for online monitoring and NDE R\&D activities of this R\&D pathway. In these R\&D areas, we are initiating our activities by collaborating with industry efforts that have common interests. Jointly planned workshops will be carried out with EPRI and utilities to initiate planning and gap analysis activities.

- Two early start R\&D activities were identified at the Ohio State University workshop that would support life-extension planning: 1) development of a long-term strategy for II\&C modernization and transformation, and 2) advanced information technologies to facilitate fleet wide integrated operations. These activities were identified by a consensus of owner/operators that participated in the Ohio State University workshop and represent several high-risk activities that are not otherwise being planned by utilities. They are supported by the vendors who attended the workshop.

- The previously mentioned activities are ongoing. The workshop report from the Ohio State University has been completed and is available to members of the Steering Committee. 
INL/EXT-09-17515

Revision 0

\section{Recommendation 35:}

XIII.B. Cost Sharing with Industry. An effective method of pooling resources needs to be developed. This requires renewed effort on carefully planning and coordinating efforts and identifying where industry could provide in-kind efforts and/or data in addition to their monetary contributions to EPRI.

Page: 50

\section{Specific Related Steering Committee Observations and Page:}

Cost Sharing with Industry. The amount and timing of cost share among the participants is not yet addressed. This issue of cost share between industry and DOE needs to be addressed in this initial planning and scheduling of the work as it could likely reduce substantially what has to be provided by DOE. Specifically, the establishment of this level of cost sharing needs early negotiation with industry since considerable difficulty in achieving cost sharing on a practical basis is anticipated. It may not be possible to set up formal cost sharing agreements on particular projects or tasks.

Resolution: Agree with recommendation.

- A cost-sharing estimation or agreements have not yet been established for these activities. At this stage of the program's life, we have been able to engage utilities, obtain their input on one key area of the II\&C program, and have had follow-on meetings in November with three of them. Duke, Entergy, and Electricite de France have indicated their willingness and have provided verbal commitment to proceed with two pilot projects:

- $\quad$ Development of a long-term strategy for establishing a modern II\&C infrastructure

- Assessment of needed technologies to enable fleet wide information and expertise integration and to begin technical exchange in areas related to the R\&D activities of this pathway.

- We are at the early stages of engagement with asset owners; cost-sharing discussions, per se, are premature. Collaboration and in-kind contributions are probably appropriate at this stage of engagement, and other arrangements will be pursued as the collaborations mature. 
INL/EXT-09-17515

Revision 0

\section{Recommendation 36:}

XIII.C. Simulation Capabilities. While the Committee points out that such a theme is not part of the Pathway, it is not unanimous in concluding that such an advanced simulation capability is needed. The alternative view is that available tools are adequate, the primary need is for more skilled practitioners in the use of these tools, and hence resources are better used in other LWRS Program areas.

The TIO should ensure these alternative views are carefully examined in reaching its own conclusion. Should the TIO schedule future Steering Committee review of this question, a comprehensive presentation of relevant considerations regarding these alternative views should be presented. This should include opportunities for the IIC Pathway to leverage from the DOE's proposed, NE-led Computation and Simulation hub should it be funded in the FY-2010 Budget.

Page: 51

\section{Specific Related Steering Committee Observations and Page:}

Simulation Capabilities. The Pathway does not propose enhanced use of simulation to support plant processes including operations, engineering, work management, and design modifications. Page 49

Resolution: Agree with recommendation.

- $\quad$ Simulation is only one kind of approach to conduct some of the R\&D proposed and planned for in this R\&D pathway. However, the industry currently regards these R\&D technologies as high risk, owing to the lack of successful demonstrations and high regulatory uncertainty. Practical demonstration facilities are needed that are representative of target applications but are far enough removed from the actual environment so that failures do not affect system operability and availability.

- $\quad$ Simulation is a cost-effective means to mock up and test approaches that require integration with realistic models of the application environment - absent the inherent risks. Simulation-based approaches will be employed to the extent feasible and appropriate. Together with simulation, other approaches to R\&D also may be employed based on the specific needs of the activity and the maturity of the technology. 
INL/EXT-09-17515

Revision 0

\section{Recommendation 37:}

XIII.D. Projects for Industry Involvement. A focused pilot project here may be attractive and provide the added advantage of relatively rapid deployment because of reduced regulatory interfaces.

Page: 51

\section{Specific Related Steering Committee Observations and Page:}

XIII.D. Projects for Industry Involvement. A focused pilot project here may be attractive and provide the added advantage of relatively rapid deployment because of reduced regulatory interfaces. Page 51

Resolution: Agree with recommendation.

- As discussed above, on the basis of the Ohio State University workshop, two head start activities have been identified and two utilities have agreed to collaborate and support. The first project is a long-term strategy for II\&C modernization that goes beyond the near-term digital system replacement of aging analog technology. The long-term strategy will focus on redefining II\&C needs in terms of potential changes and impacts to utility business models that can be achieved in the long-term through transformational II\&C technologies. This project will be carried out with Duke. The second project will be carried out initially with Entergy and will focus on information technologies needed to achieve long-term fleet wide integration of management and operation activities that have the potential to substantially reduce costs over the life of the plant.

- A meeting was held with utilities in November 2009 to establish pilot projects and follow-on plans. The follow-on plans for pilot projects are now being worked. In addition to the activities that are planned with these U.S. utilities, we are interested in developing collaborations with nuclear asset owners in other countries where digital II\&C technologies are more commonly being introduced in their nuclear fleet in order to leverage their experiences and lessons learned. Accordingly, meetings also were held with EdF in November to discuss collaboration on all areas of the II\&C pathway. These meetings occurred at three of EdF's main R\&D facilities and will be pursued in the coming calendar year to develop more formal plans and agreements for technical exchange and collaboration to augment the other United States-based collaborations that we are actively pursuing. 
INL/EXT-09-17515

Revision 0

\section{Recommendation 38:}

XIII.E. IIC Laboratory. This laboratory concept may have additional benefit beyond its current vision. Some of the inherent difficulties in the regulatory and design transition to digital technologies are the lack of focused interaction among vendors, asset owners and regulators especially in the demonstration, test and evaluation area. The IIC laboratory concept may provide a trusted third-party approach that lowers the high uncertainty of analog to digital transition. Nevertheless, the Committee is currently not unanimous in concluding that, on balance, development of this IIC laboratory is an effective use of scarce LWRS Program funding. Hence, before the Committee can come together and offer a judgment as to whether this concept should be funded, much more specificity as to its expected capabilities and role needs to be provided.

\section{Page: 51}

\section{Specific Related Steering Committee Observations and Page:}

IIC Laboratory. This laboratory concept may have additional benefit beyond its current vision. Some of the inherent difficulties in the regulatory and design transition to digital technologies are the lack of focused interaction among vendors, asset owners and regulators especially in the demonstration, test and evaluation area. The IIC laboratory concept may provide a trusted thirdparty approach that lowers the high uncertainty of analog to digital transition. Nevertheless, the Committee is currently not unanimous in concluding that, on balance, development of this IIC laboratory is an effective use of scarce LWRS Program funding. Hence, before the Committee can come together and offer a judgment as to whether this concept should be funded, much more specificity as to its expected capabilities and role needs to be provided. Page 49

Resolution: Agree that II\&C laboratory may be used beneficially at low cost to LWRS Program.

- $\quad$ The proposed II\&C laboratory will build on existing facilities and the R\&D backbone already developed at INL. This includes physical facilities in place for reconfigurable control system research, SCADA, cyber-security R\&D facilities, and visualization facilities. The advantage of using such facilities is that the capital costs have already been borne by other federal R\&D programs, and the resources that are needed are scant in order to add additional functionality needed by this program. Facility functional development will be needed to address the needs of specific R\&D activities planned in this program. No new facilities are currently envisioned, only modification of existing facilities.

- The goal for this laboratory is to serve as an independent R\&D facility in which asset owners, vendors, researchers, and regulators can conduct joint R\&D activities to develop, test, and establish the necessary regulatory technical bases to support deployment of advanced II\&C technologies for nuclear power plants. The concept for operations is similar to that of a user facility, where capabilities that are developed are available to support different user needs related to advancement of technical and regulatory capabilities. 
INL/EXT-09-17515

Revision 0

- No new acquisitions are planned for facilities as part of this R\&D pathway. R\&D capabilities will be developed in existing facilities for the purpose of conducting planned research. 
INL/EXT-09-17515

Revision 0

\section{Recommendation 39:}

XIII.F. At present funding should be allocated as follows:

Generous funding (several hundred $\mathrm{K} \$$ ) for the workshop, gap analysis and program planning task in Theme 1 as well as the overall five percent or so of funds for ongoing management of the IIC Pathway activities.

All the remaining money should be put in a reserve, pending definition of the tasks and cost share.

There may well be some tasks that can be reasonably well identified very early in the planning work and those could be funded early to get a head start on the needed work.

Page: 52

Specific Related Steering Committee Observations and Page:

See recommendation XIII A

Resolution: Disagree with recommendation. It is not practical to manage DOE funds as prescribed in the recommendation. 
INL/EXT-09-17515

Revision 0

\section{Recommendation 40:}

XIV-A. Re-scope pathway activities on a limited set of practical objectives (such as power uprates, $\mathrm{SiC}$ cladding issues, aging management performance, etc.) based on industry (and regulator) input of needs. A new licensing paradigm for license renewal should not be a pathway objective unless specifically endorsed by industry and the regulator.

\section{Page: 59}

\section{Specific Related Steering Committee Observations and Page:}

Relationship to License Renewal. The Pathway's current underlying premise is that demonstration of adequate safety margins is a significant hindrance to prospective applicants for new licenses and that RISMC projects are needed in order to make a new safety case with respect to long term operation. With respect to license renewal, this is not the case. The current regulatory process, while maybe not optimal, is stable and predictable and the current assessment is that it will continue to support subsequent renewals. It has a demonstrated record of accomplishment of over $50 \%$ of the current fleet. Introducing a new regulatory paradigm as a result of the current premise of the RISMC pathway would introduce regulatory uncertainty that neither the regulator nor the asset owners will likely support. The industry recognizes the potential value of an enhanced thermal-hydraulic modeling code. The industry no longer has the capability on its own to create a modern suite of safety analysis codes as was done at EPRI in the 1970s and 1980s, so there is great value now to industry in collaborating with DOE in code development. ----------- Given that a new safety case for sustainability is not needed, it is necessary to more definitively articulate the practical sustainability benefit that can be derived from this project since the investment is large and the schedule uncertain. For example, the code might prove very useful in achieving further core uprates. Page 57 and 58.

Resolution: Accept recommendation with reservation.

- $\quad$ The Steering Committee's observations regarding the possibly suboptimal, but currently stable, regulatory process for approving life extensions are accepted. Developing a new regulatory paradigm, at the risk of increasing programmatic uncertainties as a result, will not be a project goal.

- However, whatever the regulatory merits of a process-based rule for reviewing license renewals, utility decision-making regarding life extension will not be supported adequately by a program aimed solely at monitoring declining performance of components involved in design-basis scenarios. Even if (per EPRI recommendations) the RISMC program avoids analyzing generation risk or other topics not related to public health and safety, utility decision-making on life extension will need to consider aspects of the risk-informed part of the safety case that lie outside the scope of license renewal. 
INL/EXT-09-17515

Revision 0

- $\quad$ Therefore, while the RISMC pathway objective is not to change the licensing paradigm per se, it is necessary to establish a scientific basis and safety margin analysis tools that enable a risk-informed, performance-based safety case for life extension. A scientifically sound safety case will eventually help reduce business and regulatory uncertainty.

- In summary, the approach to resolution is the following:

- $\quad$ R\&D activities planned in FY 2010 will focus on technical development of the analysis tool needed to comprehensively analyze safety margin issues within a risk-informed paradigm.

- In expectation of further Committee review, the concept of risk-informed safety margin will be refined further, based in part on trial exercises of the analysis tool.

- $\quad$ The RISMC working group will gather experts from industry and academia to review formulation of the RISMC concept and update the strategic plan for RISMC R\&D.

- $\quad$ The RISMC working group is an activity funded in FY 2010 at \$150K to allow participation of experts (including EPRI) and develop strategic plan that addresses Recommendation 37. 
INL/EXT-09-17515

Revision 0

\section{Recommendation 41:}

XIV-B. While the RELAP-7 R\&D plan needs to be strengthened as noted in our preceding comment by better articulating its relation to the needs of LWRS, the Committee believes that the RELAP -7 project (D3.1) seems to have the most potential among the proposed Pathway tasks for long term operation impact, assuming substantive funding in order to achieve meaningful progress. The goal would be to have the RELAP -7 code contribute fully by the year 2015 to the licensing and safety analyses required for extending the life of the plants from 60 to 80 years.

Page: 59

\section{Specific Related Steering Committee Observations and Page:}

The ideas underpinning the RISMC Pathway, such as improved coupling among the thermalhydraulic, accident analysis and probabilistic risk analysis tools, are solid. The Pathway challenge is focusing on a scope that is likely to lead to concrete, practical applications over a relatively short period of time. Page 58

\section{Resolution: Agree with recommendation.}

- $\quad$ Accelerate the task on R7 code development, demonstration, and validation. In FY 2010, the R7 code project development is funded in the LWRS Program.

- In addition, an effort is being made to coordinate development of the next-generation system code R7 with activities planned and pursued in the Nuclear Energy Advanced Modeling and Simulation (NEAMS) Program and called for in the Energy Innovation Hub. Given the focus of the work under LWRS Program/RISMC on system and life extension, there are no overlaps with NEAMS (which aims at advanced reactor system design and high-resolution simulation of separate-effect physics) and with Hub (which aims at creating an engineering environment to use simulation tools). Yet, numerical experiments carried out in NEAMS and environment developed in the Hub can add to the validation and usability of the R7 code in mean time. 
INL/EXT-09-17515

Revision 0

\section{Recommendation 42:}

XIV-C. Significant industry collaboration should be pursued (including use of techniques such as a gap analysis before initiating significant work on the probabilistic risk assessment theme tasks.

Page: 60

\section{Specific Related Steering Committee Observations and Page:}

The Committee recognizes the potential value of PRA enhancements, but also recognizes the leadership role industry should have in this area. As currently proposed, plans in this area expand on today's PRA techniques, thermal hydraulics analyses, and other transient/accident analyses desiring to be exhaustive to a point where uncertainty is no longer an issue. This may lead to unrealistic data requirements for large-scale acceptance. The plan should propose specific enhancements to address specific long term operation needs. -------- The . changes in PRA need to be evolutionary to maintain continuity of safety management and other plant processes which employ PRA assessments on a regular basis. Page 58,59

Resolution: Agree with recommendation.

- The work on advanced PRA development has been delayed. However, it is noted that the objective of the RISMC pathway is to develop methodology and tools to enable safety margin characterization. Safety margin in the RISMC context is defined as the distance between the probabilistic load and the probabilistic capacity spectra. Therefore, in order to characterize safety margin, it is necessary for the probabilistic framework to be implemented in the tool (R7) that computes the load (e.g., peak clad temperature).

- The above characterization of the RISMC deliverable was discussed in the recent RISMC meeting with EPRI and industry (October 1 and 2, 2009). The RISMC Framework Project and RISMC working group will focus on overall methodology and will not pursue PRA tool development. Instead, experts in risk and reliability will participate in the R7 code project to guide formulation of the $\mathrm{R} 7$ code architecture and modeling requirements, so that the resulting $\mathrm{R} 7$ code will enable quantification of the probabilistic load. 
INL/EXT-09-17515

Revision 0

\section{Recommendation 43:}

XIV-D. Irrespective of the budget scenario, concentrate pathway resources on the RELAP-7 themed projects in order to achieve meaningful progress on tool development, delaying PRA themed activities if necessary.

Page: 61

\section{Specific Related Steering Committee Observations and Page:}

The industry recognizes the potential value of an enhanced thermal-hydraulic modeling code. The industry no longer has the capability on its own to create a modern suite of safety analysis codes as was done at EPRI in the 1970s and 1980s, so there is great value now to industry in collaborating with DOE in code development. Page 57

Of the three simplified theme areas, the theme associated with RELAP-7 has the highest potential to fill a gap in the tools desirable to support long term operation. In both the normal and reduced budget scenario, resources should be concentrated on this theme in order to make substantive progress. Page 60

Resolution: Agree with recommendation.

- $\quad$ Concentrate the developmental effort on the R7 code. The RELAP7 project is the sole development project under the work package "Enabling Methods and Tools." Funding for two other proposed developments, namely advanced PRA and advanced prevention analysis, was zeroed out in FY 2010.

- $\quad$ Given the FY 2010 budget constraint (\$2.1M for RISMC), funding planned for work package 3.1 ( $\mathrm{R} 7$ code) is $\$ 1.2 \mathrm{M}$ (i.e.. $57 \%$ of the total funding for the RISMC pathway). Still, this falls short of the Steering Committe recommendation ( $\$ 2.8$ to $3 \mathrm{M})$ for funding of the R7 code activity. 
INL/EXT-09-17515

Revision 0

\section{Recommendation 44:}

XIV-E. Generously fund planning steps and workshops that will provide the pathway with the industry's (customer's) input on the RISMC issues that have sustainability value.

Page: 61

\section{Specific Related Steering Committee Observations and Page:}

Resolution: Agree with recommendation.

- $\quad$ The pathway manager and principal investigators for the project RISMC working group and project Next Generation Code have broadened contact with industry experts and encourage their participation in the RISMC working group, R7 workshop, and R7 advisory group.

- The RISMC working group task is funded at $\$ 150 \mathrm{~K}$ to allow for participation of industry experts. Three RISMC principal investigators attended a RISMC meeting in October 2009 with EPRI and industry (utility consultants). The pathway manager and PIs communicated with experts from three major vendors, interested them with R7 development, and encouraged them to participate in the R7 advisory group (GEH and AREVA have tentatively agreed in such participation). Industry and EPRI experts are invited to the RISMC working group meeting and the R7 workshop, both scheduled in January 2010. 